\title{
A Framework for Conference Management System
}

\author{
Bharat Gupta', O.P.Gupta², B.K. Sawhney² \\ ${ }^{1}$ Research Scholar, M.Tech (CSE), \\ ${ }^{2}$ Associate Professor, School of Elect. Engineering and Information Technology, PAU, Ludhiana. \\ Email: bkg6433@yahoo.co.in, opgupta@pau.edu, bksawhney@pau.edu
}

\begin{abstract}
A conference management system (CMS) is becoming most powerful event manager for handling the international conferences. Several web based conference management systems have been developed in the paradigm of open source, which are used by most of the universities and colleges. All the conference management systems were built on webservers. The organizing process consists of very time consuming and full of paper work for event handling such as Call for papers, submission of papers by authors, review process, registration process of author and general participants. So an easy to use framework of conference management system is needed to cater the need of the non-technical people. The developed model is easy to handle and automates the process of the events one after the other without intervention of the editor, reviewer and author for developing ready to publish research papers for any organization.
\end{abstract}

\section{Keywords}

Framework; Conference management; Time complexity; Paperless work

\section{Council for Innovative Research}

Peer Review Research Publishing System

Journal: International Journal of Management \& Information Technology

\author{
Vol. 5, No. 2 \\ editor@cirworld.com \\ www.cirworld.com, member.cirworld.com
}




\section{INTRODUCTION}

Normally, conference management system involves very complicated and time consuming manual operations. In mid-90's, email become a reliable and cost-effective way to send binary files attachment and it also facilitate the possibility of sending papers electronically instead of sending through post or fax. When submission of paper increases to large extent, the task of dealing with these submissions manually for an organizer becomes difficult. This often results in problems such as noting down the wrong information of author, neglecting some submission unintentionally and slows down the process of conference organization.

Several conferences have been regularly organized worldwide each year. The organizing process involves large amount of users and consists of many major steps such as call for papers, paper submission by authors, reviews on article given by reviewers, author and general participant's registration. These activities consume resources like distributing papers to reviewers by editor, collecting the reviews results from reviewers, notifying the authors, and general participants registration.

In recent years, more and more conferences turned to online conference management systems. Conference management system typically facilitates the common tasks when organizing a conference described earlier. Generally, the system interacts with the user of which the responsibilities are divided in to four categories:

- Editor: Call for papers, assign papers to reviewers, and to take final decision on acceptance/rejection of papers.

- Reviewers: Reviewing papers and posting of comments back to editor.

- Authors: Submission of full paper with abstract and registration for conference.

- General participants: Register to attend conference but cannot present paper.

\section{RELATED WORK}

Deniz Derviz Z. et al. [4] analysed conference organization process in details and designed an automated web based conference management system that automates all the main functions needed in the management of conference. The organizing process involves call for papers, reviewing process, author/general participant's registration with the help of web based conference management system with great ease.

Noimanee Pongsathron et al. [14] discussed about the process involves in organizing online conference. This paper presents an approach to implement a conference management system using web service technology to support the work flow of conference management tasks.

\section{SYSTEM DESIGN}

Based on the conference management system requirements and the detailed analysis of a new system, the new system must be designed. This is the phase of system designing. It is the most important phase of a system. The logical system design arrived at as a result of system analysis and is converted into physical system design. The logical design produced during the analysis is turned into a physical design - a detailed description of what is needed to solve original problem. Input, output, databases, forms, codification schemes and processing specifications are drawn up in detail. In the design stage, the programming language and the hardware and software platform in which the new system will run are also decided. The design of system has a major impact on the later phases like testing and maintenance.

The design of this proposed application involved:

- Registration of Author cum participants, General participants, Reviewers.

- Devising processing methods and use of software to produce output.

- Determine the methods of data capture and data input such as HTML forms

- Designing input forms for adding new authors, participants and reviewers.

- Designing Codification Scheme.

- Documenting the design.

System design of this proposed system identified the module, specification of these modules, and how they interact with each other to produced desire output.

Various modules identified for the proposed system are as follows:

- $\quad$ Login in module.

- $\quad$ Add new conference module.

- $\quad$ Add comments to paper module.

- List of comments given by reviewers module.

- Assigned paper to reviewers by editor module. 
The architecture of conference management system is shown in the Fig [1]

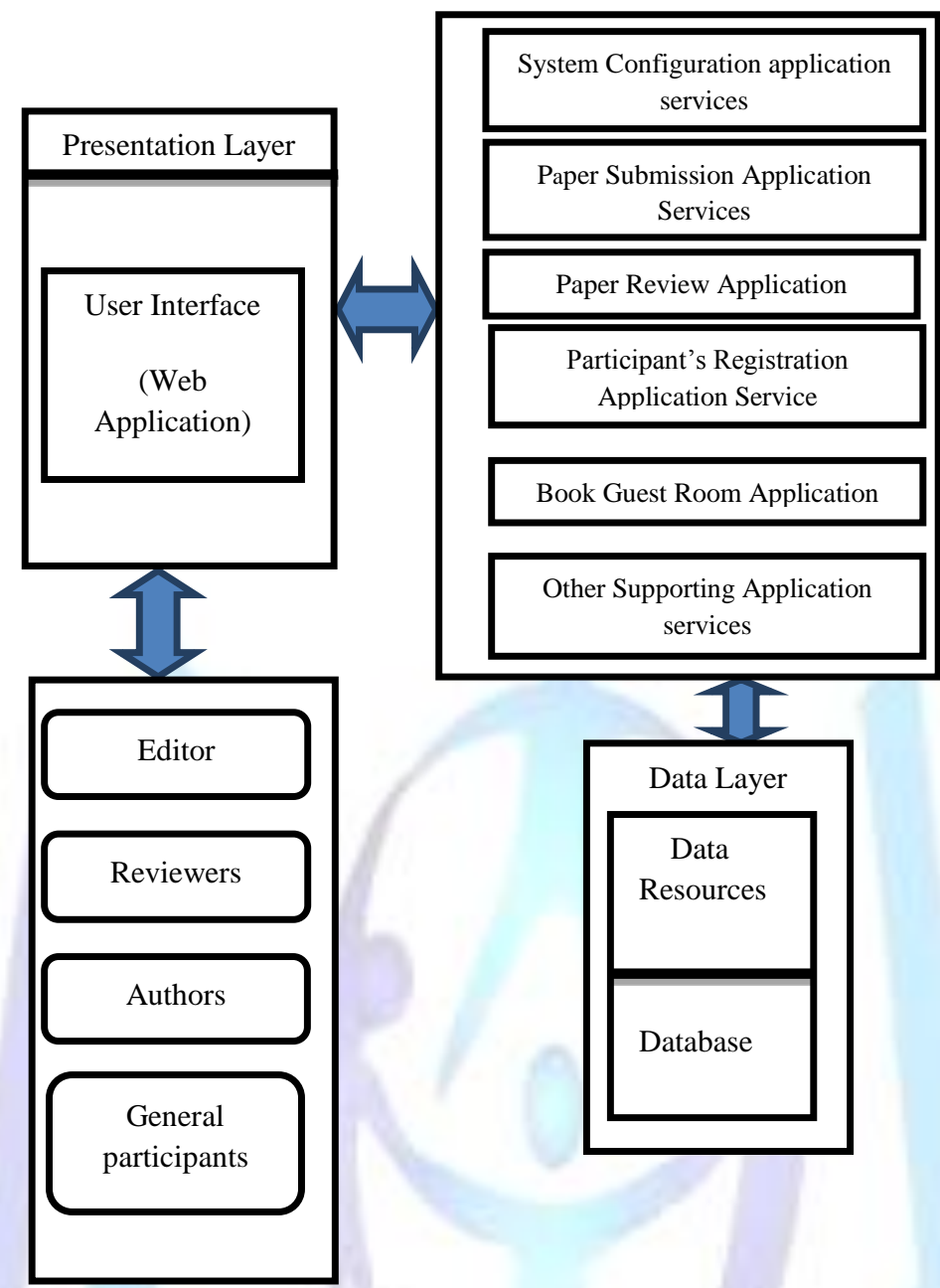

Fig1: Architecture of Conference Management System

\section{DEVELOPMENT PROCESS}

The process adopted in the development of online conference management system is based on evolutionary method employed in software engineering. In this an initial implementations is first developed and its substantiality is tested by users. The outcomes of the tests are then used to progressively refine prototype versions of the website in a sequence until such time that the site is satisfy both the user expectations and the Web operators requirements.

The first step is to determine the requirements that described earlier for the Website from the prospective of its users that is, the user's needs must be identified clearly. This involves identifying the usability requirements.

Conceptual design comes next: this normally involves conceptualising of design and architectural structure at an abstract level. Server pages, databases, and templates may be considered.

The final Website will be based on the prototype designs. Quality assurance tests are then conducted through test plans and usability testing so as to ascertain the Website functionality. The results are then utilised to improve site. Iterations are continued until the stage is reached when the site meets the specifications.

After site has been launched, it must continue to be monitored so that any flaws can be detected and rectified in a timely fashion, taking into account user feedback.

\section{RESULTS AND DISCUSSION}

Management of authors, reviewers and general participants is a very difficult task because of the participation of the authors / general participant from India as well as from abroad. The developed system helps the organiser to manage resources for all these participants and also reduces the paper work, time. Further it provides the facility of archiving the data for future use. The software has been developed by using HTML, JavaScript, PHP and MySQL.

Saving of time and paper work in terms of by putting conference registration online saves time of organiser. Saving of paper work by noting down information of each user like their name, city, place etc. With the help of conference 
management system organiser can get the prints of data of registered author cum participant, reviewers, and general participants from database. Organiser or admin can add information related to upcoming conferences of universities it helps the organiser to arrange conference in short time, and user by entering address into address bar can see the schedule of conference. Conference Management System provides facility like Upload paper, Inform about acceptance of paper, Book guest room, Registration Cancellation. Authors can upload paper online and also receives reviews from experts ; conference management system not only save time of organiser and also saves time of registered users, users can upload paper online thereby no need to send paper through courier or post. Admin can see the paper by signing in to the system and inform the different user about acceptance of the papers.

The principles of normalization are followed while designing the database so that they ensure atomicity, consistency and integrity among data. The possibility of data redundancy and invalid entries has been eliminated by implementing the validations and checks. Multiple authorized users will be able to login and logout from a web browser. Login checks (username and password) are controlled by administrator. Administrator will have total web based control to completely customize the Conference Management System. The system is user friendly. Most of the information related to conference in system can be added, viewed and updated online per individual rights.

The conference management system is designed to manage conferences and this software allows authors to upload research papers or any other publishing material on server and this software provides the functionality to the reviewers to add reviews for correction in the papers by the author. The role of editor is reduced to the extent that editor selects the reviewer from the list of experts according to expert area and subject area of paper, and then editor can take decision after considering reviews about the acceptance/rejection of papers.

\section{CONCLUSIONS}

The present study provides the simple model of conference management system, helps in reducing the paper work and handling the events in short span of time. This model can be deployed for conference of any scale. Conference management system is a part of e-governance system of any university as it reduces the time complexity and paper work. Further it enhances access to autonomous system that includes the reviewer's comments and follows up action on papers and also supports digitization of system which helps to manage conferences in short time as $50 \%$ of work is already completed with the help of online conference management system.

\section{REFERENCES}

[1] Ceri Stefano, Fraternali Piero, Matera Maristella, Maurino Andrea. Designing multi-role, collaborative Websites with WebML: a conference management system case study 2001, pages 1-23

[2] Conry Donald C. Recommender Systems for the Conference Paper Assignment Problem 2009 , pages 1-43

[3] Daimi Kevin and Li Luming. Designing an Online Conference Management System vol. 2, 2011, pages 1-8

[4] Deniz Dervis Z., Bulancak Atilla. WEB-BASED CONFERENCE MANAGEMENT SYSTEM 2007, pages 1-8

[5] Gol Ozdemir, Nafalski Andrew, NguyenThein D., Tran Quang T. The Development of online conference mgt. tool 2004.vol.8, pages 183-188

[6] Huang M., Y. Feng, B.C. Desai . CONFSYS2: An Improved Web-Based Multi-Conference Management System, Proceedings of the 2009 C3S2E conference

[7] Jain Madhur, TewariTribhuwan K., Singh Sandeep K. Open issues in organising computer systems conferences. ACM SIGCOMM Computer Communication Review2008 vol. 38, pages 93-101

[8] K. Akagi and T. Furukawa Feasibility Implementation of Paper Submission and Publication Support System over the Internet, Proceedings of SICE Annual Conference, Fukui, Japan. SICE,2003 vol. 2, pages 1681-1686

[9] Kalmukov Yordan Architecture of a conference management system providing advanced paper assignment features. 2011 vol. 34 (3), pages 51-59

[10] Mauro Nicola Di, Basile Teresa M.A , Ferilli Stefano An Expert Review Assignment Component for Scientific Conference Management Systems 2005, pages 789-798

[11] Mete Eren, Ak Merve, Akın Umut, Sucu Gunes A Conference Management and Hosting System 2012, pages 13

[12] Mirjana Ivanovic, Putnik Zoran, Budimac Zoran Conference Workflow - a Formalization of a Conference Management Process 2003, pages 58-66

[13] Mogul Jeffrey C., Anderson Tom Open Issues in Organizing Computer Systems Conferences 2008 vol 38 , pages 93-101

[14] NoimaneePongsathron, LimpiyakronYachai Towards a Restful Process of conference Management System. IMECS,2009 vol. 1, pages 1-6

[15] Pesenhofer Andreas, Mayer Rudolf , Rauber Andreas Improving Scientific Conferences by Enhancing Conference Management Systems with Information Mining Capabilities 2006, pages 1-8

[16] Rigaux LRI Philippe An Iterative Rating Method: Application to Web-based Conference Management 2004, pages 1-12

[17] Santos Danilo, Blois Marcelo, Bastos Ricardo Developing a conference mgt. system with the multi-agent systems unified process. Av. IPIRANGA6681,2007, pages 1-12

[18] Scacchi Walt Understanding the Requirements for Developing Open Source Software Systems 2002, pages 1-26

[19] Stadt Richard van de A web-based groupware application to facilitate the paper reviewing process 2008, pages $1-15$

[20] ZhengC.,ShenW., ZhengQ.,TianF. Design and implementation of a collaborative conference management 
system.NRCC 50288, 2008 , pages 5-10

\section{Author' biography with Photo}
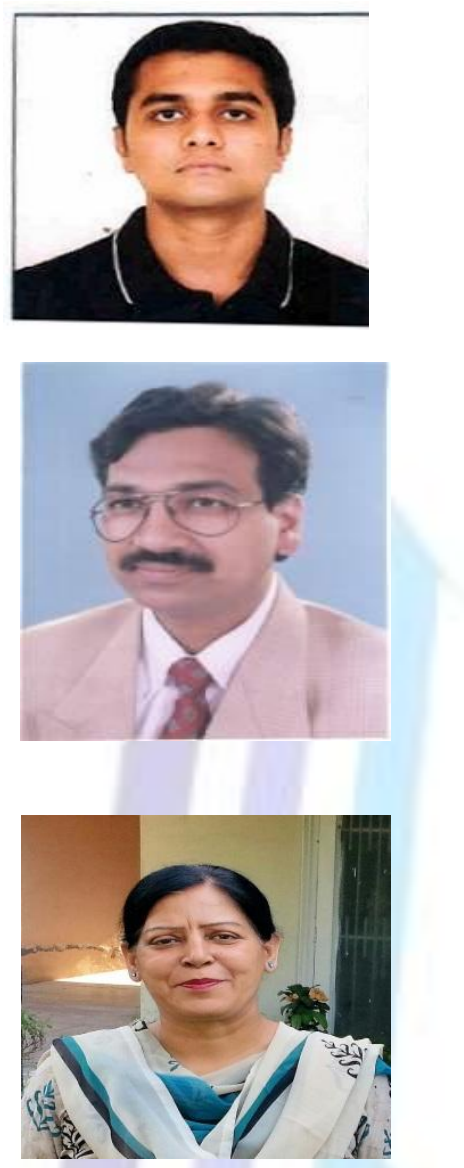

Er. Bharat Gupta received B.Tech (Computer Engineering) form Punjabi University College of Engineering \& Management Rampura Phul, India in 2011 and pursuing M.Tech degree in (Computer Science \& Electrical Engineering) from Punjab Agricultural University Ludhiana, India. Email: bkg6433@yahoo.co.in

Dr. O P Gupta, an alumni of PAU, Ludhiana, Thapar University, Patiala and GNDU, Amritsar has demonstrated his intellectual, interpersonal and managerial skills in various domains. He is bestowed with PAU Meritorious Teacher Award for 2009-10. Having vast industrial experience of working in IT industry with the role of Project Leader and Project Manager, currently he is Associate Professor of Computer Science and Deputy Director, School of Elect.Engg. \& Information Technology at PAU, Ludhiana. His areas of interests include Parallel and Distributed Computing, Grid Computing for Bioinformatics, Network Testing and Network Management. Along with being a committed teacher and a passionate researcher, he is actively involved in social activities. Email: opgupta@pau.edu

Dr. B.K. Sawhney is working as an Associate Professor in the School of Elect.Engg. \& Information Technology, Punjab Agricultural University. Her qualification are B.S.C (Non Medical), B.Tech (Electrical Engg.), M.Tech (Instrumentation) and Ph.D in the field of Electronics Technology. She was twenty five years experience of teaching Under-Graduate and Post-Graduates students. She has published many research papers in National and International Journals and Conferences. Email: bksawhney@pau.edu 